REVIEW ARTICLE

\title{
Sleep Apnea / Hypopnea Syndrome - A Review
}

\author{
Pravesh Mehra \\ Oral \& Maxillofacial Surgery, Lady Hardinge Medical College and Associated Hospitals
}

New Delhi 110001

\begin{abstract}
The sleep apnoea/ hyperpnoea syndrome is characterized by repeated upper airway narrowing or collapse during sleep. These episodes are accompanied by hypoxemia, surges in blood pressure, brief arousal from sleep and pronounced snoring. The signs and symptoms of OSAS may be recognizable in the practice of Dental and Oral Maxillofacial surgery. Common findings in the medical history include day time sleepiness, snoring, hypertension, and type 2 diabetes mellitus. Common clinical findings include male gender, obesity, increased neck circumference, excessive fat deposition in the palate, tongue (macroglossia) and pharynx, a long soft palate, a small recessive maxilla and mandible, and calcified carotid artery atheroma on panoramic and lateral cephalometric radiograph. After confirmation of the diagnosis by a physician, Dental surgeons and Oral maxillofacial surgeons can participate in the management of the disorder by fabricating mandibular advancement appliances that enlarge the retroglossal space by anterior displacement of tongue, and performing corrective upper airway surgery that prevents recurrent airway obstruction respectively.
\end{abstract}

Indian J Sleep Med 2007; 2.1, 11-14

\section{Incidence}

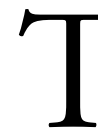
$\checkmark$ he incidence of OSAS in the middle aged population (30-60 years) is $4 \%$ in men and $2 \%$ in women (1). However, incidence rises dramatically with age, to an estimated $28 \%$ to $67 \%$ for elderly men and $20 \%$ to $54 \%$ for elderly women (2).

\section{Clinical Manifestations}

OSAS is characterized by repetitive episodes of upper airway obstruction that occur during sleep usually in association with a reduction in blood oxygen saturation. Patients may report that they frequently fall asleep during the day while driving, working, reading and watching television (3). This leads to reduced productivity and poor work output. Also performing activities related to transportation or the use of

Address for correspondence:

Dr. Pravesh Mehra

Associate Professor

Oral \& Maxillofacial Surgery

Lady Hardinge Medical College and Associated

Hospitals, New Delhi 110001 machinery and heavy equipment can put both the patient and others at significant risk of injury $(4,5)$. Snoring ranging in severity from mild to extremely loud is invariably present. OSAS patients may witness gasping, choking or periods of apnea, with repeated arousals through the night. When questioned in the morning the patient is usually unaware of the frequency of the arousals. Other complaints include a feeling of not being rested despite a full night of sleep, dry mouth, morning headache, absence of dreams, fatigue, decreased libido, and symptoms of depression. In many cases these symptoms are so severe that the partner sleeps in another room.

The respiratory consequences of OSAS are related to the extent of hypoxemia and hypercapnia that develop as a result of the disordered breathing. Advanced cases of OSAS are associated with pulmonary hypertension, corpulmonale, chronic carbon dioxide retention and polycythemia (6). The cardiovascular consequences of OSAS may include systemic hypertension, cardiac arrhythmias, myocardial infarction, and cerebral vascular accidents, all of which lead to a higher mortality rate than in the general population $(7,8)$.

Thus OSAS can be a debilitating and potentially life

Indian Journal of Sleep Medicine (IJSM), Vol. 2, No. 1, 2007 
threatening condition. Both proper diagnosis and appropriate treatment as soon as possible are important.

\section{Diagnostic Aids}

If the history supports the diagnosis of OSAS, the patient should be referred to a sleep disorders laboratory for the over night polysomnography, the objective method of establishing the diagnosis and assessing the potential success of treatment. The most important variables used in determining the presence and severity of OSA are the apnea index, the hypopnea index, the respiratory disturbance index (RDI) and the lowest oxyhemoglobin saturation (9). Apnea is defined as cessation in air flow for 10 seconds or more, and the apnea index is the number of apneic episodes occurring in a 1 hour period (10). Hypopnea has been defined as a $50 \%$ reduction in tidal volume for more than 10 seconds, and the hypopnea index is the number of hypopneic episodes in a 1 hour period (10). The RDI is defined as the number of apneic and hypopneic episodes per hour of sleep (10). The lowest oxyhemoglobin saturation is simply the lowest oxygen saturation measured by pulse oximetry during the study. OSAS is diagnosed if the RDI reaches a certain threshold level, typically 5 or $10(2,10)$. OSAS becomes clinically significant when the RDI is greater than 20 and oxygen desaturation events fall to a level below $80 \%$ to $85 \%(11)$.

\section{Pathophysiology}

OSAS is mainly caused by an anatomic abnormality that narrows or obstructs the airway. Obstruction more commonly occurs at multiple levels of the upper airway during episodes of hypopnea and apnea (12). In any patient, upper airway patency is maintained through many interrelated anatomic and physiologic factors (13). The pharynx consists of 3 segments: the nasopharynx, the oropharynx, and the hypopharynx. The muscles become hypotonic during sleep, and airway stability becomes dependent on pharyngeal size and pharyngeal tissue compliance in these 3 segments $(13,14)$. Airway obstruction occurs if the compliance of the soft tissues in the narrowed segments of the passive airway is inadequate to offset the negative intraluminal pressure created during inspiration. Thus, the central nervous system adjusts to a lighter level of sleep by increasing muscle tone to allow opening of the airway and resumption of the breathing cycle.

Many a times, clinical examination will not reveal a gross oro-facial deformity, but upper airway imaging eg cephalometric radiography can help in determining the anatomic factors contributing to OSAS. This can help in the treatment planning, particularly Orthognathic surgery, and thus lead to more predictable treatment outcomes. Cephalometric studies in patients with OSAS have demonstrated that these patients have smaller retro positioned mandibles, narrower posterior airway space, and larger tongues and soft palates than control patients, as well as inferiorly positioned hyoid bones and retro positioned maxillae (15).

\section{Management}

OSAS patients can be treated non-surgically (conservative method) or surgically.

The severity of the patients' condition is considered in developing a treatment plan. The treatment plan should take into account the potential contributing factors identified by the history, clinical examination and cepalometric studies.

\section{Conservative management}

As obesity is a risk factor for OSAS, body weight reduction can help reduce sleep apnea $(16,17)$. However, the patient may have difficulty in losing weight, mainly in more severe cases. Also many patients with OSAS are not obese.

The most successful conservative method is using CPAP (continuous positive airway pressure). Sullivan et al in 1981 first described the use of CPAP in the treatment of OSAS (18). Since then it has become the gold standard in the treatment of this condition (9). However, the compliance of using the equipment may be as low as $46 \%$ (19). It is mainly because of physical discomfort associated with wearing the unit, drying of the nasal and oral mucosal membranes, dislodgement during sleep, noise and the social consequences of using the unit.

Medicines such as protriptyline and medroxyprogesterone are used. Protriptyline, a tricyclic antidepressant, has shown reasonable symptomatic improvement of OSAS and may reduce the degree of oxygen desaturation, but anticholinergic side effects and incomplete efficacy limit its use (6). Medroxyprogesterone has limited value in the treatment of OSAS but it may be effective in cases of obesity hypoventilation syndrome with chronic hypercapnia (6). 
Myofunctional oral appliances can also be used in the treatment of OSAS (20). Schmidt- Nowara et al 1995 (21), reviewed 20 studies, involving a total of 304 patients, and showed that oral appliances were effective in $51 \%$ of cases, as defined by an achievement of RDI of less than 10. In 2 studies that compared oral appliances for mandibular advancement with CPAP, the oral appliances were effective in mild to moderate cases but were less effective than nasal CPAP in more severe cases $(22,23)$. In both these studies patients strongly preferred the myofunctional oral appliances over nasal CPAP for reasons of comfort. However, long term effects of oral appliances are temporomandibular joint problems and movement of teeth (24). Teeth movement may result in posterior open bite and decreased anterior overjet (20).

\section{Surgical Management}

Fee WE etal in 1970 introduced tracheostomy as the first successful surgical treatment of OSAS (25). This procedure, which bypasses the upper airway, is successful in virtually $100 \%$ of the cases (26). The medical complications and social problems associated with tracheostomy have stimulated the search for alternatives (6).

Fujita etal in 1981 first described the use of uvulopalatopharyngoplasty (UPPP) for the treatment of OSAS (27). This procedure involves resecting tissues from the free border of the soft palate (including the uvula), posterior tonsillar pillars, the palatine tonsils (if still present) and excessive mucosa from the anterior pillars and posterior pharyngeal walls using a scalpel and general anesthesia in a hospital operating room (28-29). This procedure is associated with significant post operative discomfort and may result in palatal incompetence with nasal regurgitation on swallowing and nasal speech.

In the 1970 s, orthognathic surgery (mandibular advancement) was first used for the treatment of OSAS (30). Orthognathic surgery for the treatment of OSAS may involve advancement of maxilla, mandible or chin. Cephalometric analysis allows precise planning of the surgical advancement to maximize the increase in pharyngeal dimensions while maintaining normal facial balance.

If the patient is retrognathic and the respiratory obstruction is occurring at the base of the tongue, an oral and maxillofacial surgeon will advance the entire mandibular alveolus forward and reposition it into a physiologic Class I position. The anterior movement of the alveolus is accompanied by anterior movement of the tongue (away from the posterior pharyngeal wall) because the tongue is attached to the lower jaw at the genial tubercles. The tongue can be drawn even further anteriorly by performing a genioplasty which encompasses the genial tubercles (31).

If the patient is not retrognathic, and the respiratory obstruction is documented as occurring at the base of tongue and/or soft palate, simultaneous advancement of the maxilla and mandible is indicated. The results of this surgery while not always an esthetic do appear to obviate OSAS in most instances (32).

Orthognathic surgery is more socially accepted in comparison to tracheostomy and CPAP. Also compliance is not a factor in the success of orthognathic surgery as it is for CPAP and oral appliances. It is also more successful in treating severe OSAS than UPPP and oral appliances.

\section{Conclusion}

OSAS is a common condition associated with significant morbidity and mortality. It is therefore important that Dental and Oral maxillofacial professionals be aware of the signs and symptoms of OSAS, so that the diagnosis can be confirmed and treatment initiated as soon as possible in association with the physicians. Orthognathic surgery by oral and maxillofacial surgeons and myo-functional appliances by dental surgeons appears to be an excellent treatment option, in patients with identifiable anatomic abnormalities of the jaw bones, resulting in a narrow pharyngeal airway.

\section{References}

1. Young T, Palta $M$, Dempsey J, Weber S, Badr S. The occurrence of sleep-disordered breathing in middle-aged adults. N Engl J Med 1993; 328(17): 1230-5.

2. Goodday RH. Nasal respiration, nasal airway resistance, and obstructive sleep apnea syndrome. Oral Maxillofac Surg Clin North Am 1997; 9(2): 167-77.

3. Bahammam A, Kryger M. Decision making in obstructive sleep disordered breathing: putting it all together. Otolaryngol Clin North Am 1999; 32(2):333-48.

4. Findley LJ, Fabrizio $M M$, Knight $H$, Norcross $B B$, La Forte AJ, Surratt PM. Driving simulated performance in patients with sleep apnea. Am Rev Respir Dis 1989; 140(2):529-30.

5. George CF, Boudreau AC, Smiley A. Simulated driving performance in patients with sleep apnea. Am J Respir Crit Care Med 1996; 154(1): 175-81.

6. Wiggins RV, Schmidt-Nowara WW. Treatment of the obstructive sleep apnea syndrome. West J Med 1987; 147(5): 561-8.

7. He J, Kryger MH, Zorick FJ, Conway W, Roth T. Mortality 
and apnea index in obstructive sleep apnea. Experience in 385 male patients. Chest 1988; 94(1): 9-14.

8. Shepard JW Jr. Hypertension, cardiac arrhythmias, myocardial infarction, and stroke in relation to obstructive sleep apnea. Clin Chest med 1992; 13(3): 437-58.

9. Troell RJ, Riley RW,Powell NB, Li K. Surgical management of the hypopharyngeal airway in sleep disordered breathing. Otolaryngol Clin North Am 1998; 31 (6): 979-1012.

10. Riley RW, Powell NB, Guilleminault C. Maxillary, mandibular, and hyoid advancement for treatment of obstructive sleep apnea: a review of 40 patients. J Oral maxillofac Surg 1990; 48(1): 20-6.

11. Riley RW, Powell N, Guilleminault C. Current surgical concepts for treating obstructive sleep apnea syndrome. $J$ Oral Maxillofac Surg 1987; 45(2): 149-57.

12. Guilleminault C, Hill MW, Simmons FB, Dewent WC. Obstructive sleep apnea: electromyographic and fiberoptic studies. Exp Neurol 1978; 62(1): 48-67.

13. Remmers JE, DeGroot WJ, Sauerland EK, Anch AM Pathogenesis of upper airway occlusion during sleep. J Appl Physiol 1978; 44(8): 931-8.

14. Lowe AA, Santamaria JD, Fleetham JA, Price C. Facial morphology and obstructive s;eep apnea. Am J Orthod Dentofacial Orthop 1986; 90(6): 484-91.

15. Schwab RJ, Goldbert AN. Upper airway assessment: radiographic and other imaging techniques. Otolaryngeal Clin North Am 1998; 31(6): 931-68.

16. Loube DI, Loube AA, Mitler MM. Weight loss for obstructive sleep apnea: the optimal therapy for obese patients. J Am Diet Assoc 1994; 94(11): 1291-5.

17. Strobel RJ, Rosen RC. Obesity and weight loss in obstructive sleep apnea: a critical review. Sleep 1996; 19(2): 104-15.

18. Sullivan CE, Issa FG, Berthon- Jones M, Eves L. Reversal of obstructive sleep apnes by continuous positive airway pressure applied through the nares. Lancet 1981; 1(8225): 862-5.

19. Sanders MH, Gruendl CA, Rogers RM. Patient compliance with nasal CPAP therapy for sleep apnea. Chest 1986; 90(3): 330-3.

20. Milman RP, Rosenberg $\mathrm{Cl}$, Kramer NR. Oral appliances in the treatment of snoring and sleep apnea. Otolaryngeal Clin North Am 1998; 31(6): 1039-48.
21. Schmidt- Nowara W, Lowe A, Wiegand L, Cartwright R, Perez- Guerra F, Menn S. Oral appliances for the treatment of snoring and obstructive sleep apnea: a review. Sleep 1995; 18(6): 501-10.

22. Clark GT, Blumenfeld I, Yoffe N, Peled E, Lavie P. A crossover study comparing the efficacy of continuous positive airway pressure with anterior mandibular positioning devices on patients with obstructive sleep apnea. Chest 1996; 109(6): 1477-83.

23. Ferguson KA, Ono T, Lowe AA, Keenan SP, Fleetham JA. A randomized crossover study of an oral appliance vs nasalcontinuous positive airway pressure in the treatment of mildmoderate obstructive sleep apnea. Chest 1996; 10(5)9: 1269-75.

24. Panula K, Keski-Nisula, K. Irreversible alteration in occlusion caused by a mandibular advancement appliance: an unexpected complication of sleep apnea treatment. Int J Adult Orthodon Orthognath Surg 2000; 15(3): 192-6.

25. Fee WE Jr, Ward PH. Permanent tracheostomy: a new surgical technique. Ann Otol Rhinol Laryngol 1977; 86(5 P+1):635-8

26. Michelson SA. Upper airway bypass surgery for obstructive sleep apnea syndrome. Otolaryngol Clin North Am 1998; 31(6): 1013-23.

27. Fujita S, Conway W, Zorick F, Roth T. Surgical correction of anatomic abnormalities of obstructive sleep apnea syndrome; uvulopalatopharyngoplasty. Otolaryngol Head Neck Surg 1981; 89(6):923-34.

28. Carney AS, Robinson PJ. Assessment and management of snoring: a surgical perspective. BJ Hosp Med 1995; 53:512 515.

29. Battagel JM. Obstructive sleep apnea: fact not fiction. Br J Orthod 1996; 23: 315-324.

30. Bear SE, Priest JH. Sleep apnea syndrome; correction with surgical advancement of the mandible. J Oral Surg 1980; 38(7):543-9.

31. Waite PW, Wooten V, Lachner J, Gayett RE Maxillomandibular advancement surgery in 2 patients with obstructive sleep apnea. J Oral Maxillofac Surg 1989; 47: 1256-1261.

32. Waite PD, Shttar SM. Maxillomandibular advancement surgery: a cure for obstructive sleep apnea syndrome. Oral Maxillofac Surg Clin N Am 1995; 7: 327-336. 